\title{
MEMACU KUALITAS SDM DI TENGAH PANDEMI COVID-19 DI RUMAH TAHFIDZ AL HIKAM, KEL. PONDOK KACANG TIMUR, KEC. PONDOK AREN. TANGERANG SELATAN
}

\author{
Hira Maulida, Muhamad Abid, Dede Andi, Melda Wiguna, Irfan Rizka Akbar \\ Universitas Pamulang \\ Email: dosen02450@unpam.ac.id
}

\begin{abstract}
This community service activity aims to motivate and provide counseling in managing and thinking about effective governance on solutions to develop the potential of students and santri teachers in spurring the quality of human resources as an effort to achieve the goal of building the economy for the Al-Hikam tahfidz house. The program we are proposing is "Spurring the Quality of Human Resources in the Middle of the Covid-19 Pandemic at Tahfidz Al Hikam's House, Kel. Pondok Kacang Timur, Kec. Pondok Aren, South Tangerang ". The form of this program is to spur the quality of human resources by counseling on human resource development which has a positive impact on the students and teachers of the tahfids and tahsin AlHikam houses to be able to become competent human resources. The methods that will be used in achieving the goals are various methods such as lectures, discussions and questions and answers, as well as regular community assistance. This program has long-term results and goals for the human resources of Rumah Tahfidz to become more competent and qualified for supplies in the future.
\end{abstract}

\section{Keywords: HR Development, HR Education}

\begin{abstract}
Abstrak
Kegiatan pengabdian kepada masyarakat ini bertujuan untuk memotivasi dan memberikan penyuluhan dalam mengelola dan memikirkan tata kelola yang efektif tentang solusi mengembangkan potensi para santri maupun para guru santri dalam memacu kualitas SDM sebagai upaya pencapaian tujuan untuk membangun perekonomian untuk rumah tahfidz Al - Hikam. Program yang kami usulkan adalah "Memacu Kualitas SDM di Tengah Pandemi Covid-19 Pada Rumah Tahfidz Al Hikam, Kel. Pondok Kacang Timur, Kec. Pondok Aren, Tangerang Selatan”. Bentuk dari program ini adalah memacu kualitas SDM dengan Penyuluhan Pengembangan SDM yang dampak positifnya bagi para santri maupun tenaga pengajar para rumah tahfids dan tahsin Al-Hikam untuk mampu menjadi SDM yang kompeten. Metode yang akan dipakai dalam pencapaian tujuan yaitu dengan berbagai metode seperti ceramah, diskusi dan tanya jawab, serta pendampingan bagi masyarakat secara rutin. Program ini mempunyai mempunyai hasil dan tujuan jangka panjang demi SDM Rumah Tahfidz menjadi lebih kompeten dan berkualitas untuk perbekalan di masa yang akan datang.
\end{abstract}

Kata Kunci : Pengembangan SDM, Pendidikan SDM 


\section{A. PENDAHULUAN}

Meningginya kasus tingkat pengangguran adalah hal yang krusial dialami oleh dampak covid-19 dalam masa pandemi. Pengangguran di Indonesia yang telah mencapai puluhan juta orang merupakan suatu masalah yang mendesak yang harus segera dipecahkan karena dampak pengangguran itu akan sangat berbahaya bagi tatanan kehidupan sosial. Upaya-upaya pemberdayaan masyarakat dalam meningkatkan sumber daya manusia guna mengatasi pengangguran adalah dengan melalui pelatihan yang berdasarkan kompetensi yang dibutuhkan, memberdayakan kegiatan belajar yang ada dengan berbagai keterampilan ekonomi produktif, meningkatkan hubungan antara lembaga pendidikan dan industri sehingga relevansi pendidikan dapat ditingkatkan, memperkuat landasan kultural pendidikan sebagai terapi budaya, dan mendorong serta membangkitkan semangat di Rumah tahfidz Al Hikam.

Sumber daya manusia merupakan potensi yang terkandung dalam diri manusia untuk mewujudkan perannya sebagai makhluk sosial yang adaptif dan transformatif yang mampu mengelola dirinya sendiri serta seluruh potensi yang terkandung dialam menuju tercapainya kesejahteraan kehidupan dalam tatanan yang seimbang dan berkelanjutan. Sumber daya manusia yang kompeten dan berkualitas sangat dibutuhkan dalam upaya mendukung produktivitas dan aktivitas agar tujuan negara dapat tercapai dengan sempurna. Sumberdaya manusia juga merupakan faktor kunci dalam reformasi ekonomi, yakni bagaimana menciptakan sumber daya manusia yang berkualitas dan memiliki keterampilan serta daya saing yang tinggi dalam persaingan global. Salah satu hambatan mendasar yang dihadapi dalam proses pembangunan di negara yang sedang berkembang seperti Indonesia adalah tidak tersedianya dana yangcukup. Hambatan ini menyebabkan terbatasnya pula upaya menjadikan sumber daya manusia di Indonesia ini menjadi berkualitas. Padahal pembangunan infrastruktur dibutuhkan untuk memfasilitasi pertumbuhan ekonomi, yang akan meningkatkan kualitas SDM.

Secara konseptual pembangunan adalah segala upaya yang dilakukan secara terencana dalam melakukan perubahan dengan tujuan utama memperbaiki dan meningkatkan taraf hidup masyarakat, meningkatkan kesejahteraan dan meningkatkan kualitas manusia. Pembangunan nasional seharusnya diarahkan untukmencapai keberhasilan ini yaknipeningkatan harkat dan martabat bangsa. Masalah sumber daya manusia (SDM) inilah yang menyebabkan proses pembangunan yang berjalan selama ini kurang didukung oleh produktivitas tenaga kerja yang memadai. Investasi sumber daya manusia adalah suatu biaya yang harus dikorbankan baik dalam bentuk uang, waktu, maupun kesempatan untuk membentuk modal manusia yang lebih baik di masa depan. Sedangkan modal manusia (human capital) adalah istilah yang sering digunakan oleh para ekonom untuk pendidikan, kesehatan, dan kapasitas manusia yang lain yang dapat meningkatkan produktivitas jika halhal tersebut ditingkatkan. Produktivitas yang tinggi akan memacu laju pertumbuhan output secara agregat lebih tinggi.

Untuk menghasilkan sumberdaya manusia yang berkualitas, maka pendidikan merupakan suatu hal yang penting dan untuk itu peningkatan kualitas sumber daya manusia mutlak harus dilakukan. Karena dengan kualitas sumber daya manusia yang berkualitas dapat memberikan multiplier efect terhadap pembangunan suatu negara, khususnya pembangunan bidang ekonomi.Pengembangan kualitas sumber daya manusia sendiri adalah upaya pengembangan manusia yang menyangkut pengembangan aktifitas dalam bidang pendidikan, latihan, kesehatan dan gizi. Pengertian ini memusatkan pada pemerataan dalam meningkatkan kemampuan manusia dan pada pemanfaatan kemampuan tersebut.(Sein, 2009). 
Pendidikan diyakini sebagai salah satu bidang yang memiliki peran pentingdan strategis dalam pembangunan suatu bangsa. Bahkan menjadi faktor dominan didalam proses peningkatan kecerdasan bangsa. Betapa penting dan strategis perananpendidikan di dalam pembangunan bangsa, hal tersebut telah diakui sejak dirumuskannya UUD 1945. Tanpa bangsa yang cerdas tidak mungkin bangsa itu ikut serta dalam percaturan global.

Secara umum, terdapat dua orientasi pendidikan dalam pembangunan bangsa, yaitu orientasi individual dan orientasi masyarakat. Orientasi individual,pendidikan berperan dalam pembentukan insan terdidik (educated person) yaitu melalui proses pengembangan potensi diri. Kemampun yang dimiliki oleh insan terdidik merupakan sarana bagi pemahaman diri dan lingkungan, upaya adaptasi dan partisipasi dalam perubahan, pelaku utama bagi perubahan (inovator), dan memiliki orientasi prediktif dan antisipatif. Dengan demikian, manusia terdidik dapat menjadi anutan bagi yang lainya (reference behavior) dan memiliki andil dalam membangun masyarakat (society building).

Untuk itu, manusia terdidik harus memiliki keunggulan partisipatif bagi terwujudnya transformasi sosial yang menyeluruh. Sedangkan orientasi masyarakat, pendidikan memiliki tiga peran utama yakni sebagai agen konservatif (agent of conservation), agen inovatif (agent ofinnovation), dan agen perubahan (agent of change). Sebagai agen konservatif, pendidikan secara operasional praktis melalui kegiatan pembelajaran yangberorientasi pada penanaman dan pelestarian nilai-nilai sosial-budaya asli (indigeneous) yang memiliki ketangguhan dan ketahanan (homeostatic). Dengan demikian, masyarakat akan memiliki jati diri dalam menyikapi arus globalisasi. Sebagai agen inovatif, pendidikan memiliki peran dalam mengembangkan ilmu pengetahuan, mendesiminasikan, mensosialisasikan, dan mengaplikasikannya.

Melalui perannya tersebut, pendidikan akan menghasilkan masyarakat pembelajar (learning society) yang diekspresikan dengan gemar mencari informasi, menggunakan, dan mengkomunikasikannya. Sedangkan sebagai agen perubahan, pendidikan memiliki konsekuensi terhadap aplikasi dari produk inovasi pendidikan, sehingga pendidikan menjadi katalisator bagi terjadinya transformasi sosial. Pendidikan tidak hanya berorientasi pada masa sekarang, melainkan bersifat dinamis dan antisipatif bagi terjadinya perubahan.

\section{B. METODE PELAKSANAAN}

Kegiatan pengabdian kepada masyarakat ini kami rencanakan akan dilaksanakan selama dua hari yaitu pada hari Sabtu 3 Oktober 2020 s/d Minggu 4 Oktober 2020. Persiapan kegiatan dilakukan dengan mempersiapkan segala sarana dan prasarana untuk pelaksanaan kegiatan Pengabdian Kepada Masyarakat mulai dari koordinasi dengan semua peserta PKM dan Pihak Rumah Tahfidz Al Hikmah, menyiapkan materi pembinaan, konsumsi hingga transportasi. Kegiatan PKM dimulai dengan doa serta perkenalan dari ketua dan para anggota pelaksana. Adapun kegiatan tersebut dilakukan di Aula Rumah Tahfidz Al Hikmah, Kel. Pondok Kacang Timur, Kec. Pondok Aren Tangerang Selatan dengan mempresentasikan materi pembinaan dan penyuluhan yang disampaikan oleh semua anggota pelaksanaan kegiatan Pengabdian Kepada Masyarakat. Kemudian kegiatan diskusi, tanya jawab serta sharing mengenai permasalahan yang berkaitan dengan tema PKM hingga dapat memberikan manfaat pada peserta PKM. Pada hari Sabtu 3 Oktober 2020 yaitu diawali dengan kegiatan persiapan dan gladi resik yang diikuti oleh semua dosen pengabdi, mahasiswa dan beberapa guru dan santri dari Rumah Tahsin dan Tahfidz Al-Hikam, yang mana persiapan tersebut berupa penyiapan tempat, peralatan maupun perlengkapan kegiatan. Pengabdian terhadap masyarakat ini diharapkan membantu SDM Rumah tahfidz Al Hikam baik peningkatan 
kualitas SDM serta bagaimana mendidik siswa dengan akhlakul karimah yang baik dengan mengajarkan norma-norma yang baik dalam masyarakat.

\section{HASIL DAN PEMBAHASAN}

Kegiatan Pengabdian Kepada Masyarakat di Rumah tahfidz Al Hikam dihadiri 30 orang yang terdiri dari perwakilan ketua Yayasan Tahsin Al Hikam dan para santri satriwati serta tenaga pengajar, Serta seluruh anggota pengabdi yaitu para dosen dan mahasiswa Universitas Pamulang. Kegiatan dilaksanakan melalui ceramah, diskusi tanya jawab mengenai bagaimana upaya memacu kualitas SDM di tengah Pandemi. Selain itu para narasumber memberikan penyuluhan dan pelatihan yang diikuti oleh para peserta yang kumpul di Aula rumah tahfidz Al Hikam. Kegiatan berjalan lancar, peserta antusias untuk berdiskusi serta para narasumber lebih bersemangat untuk memberikan penyuluhan.
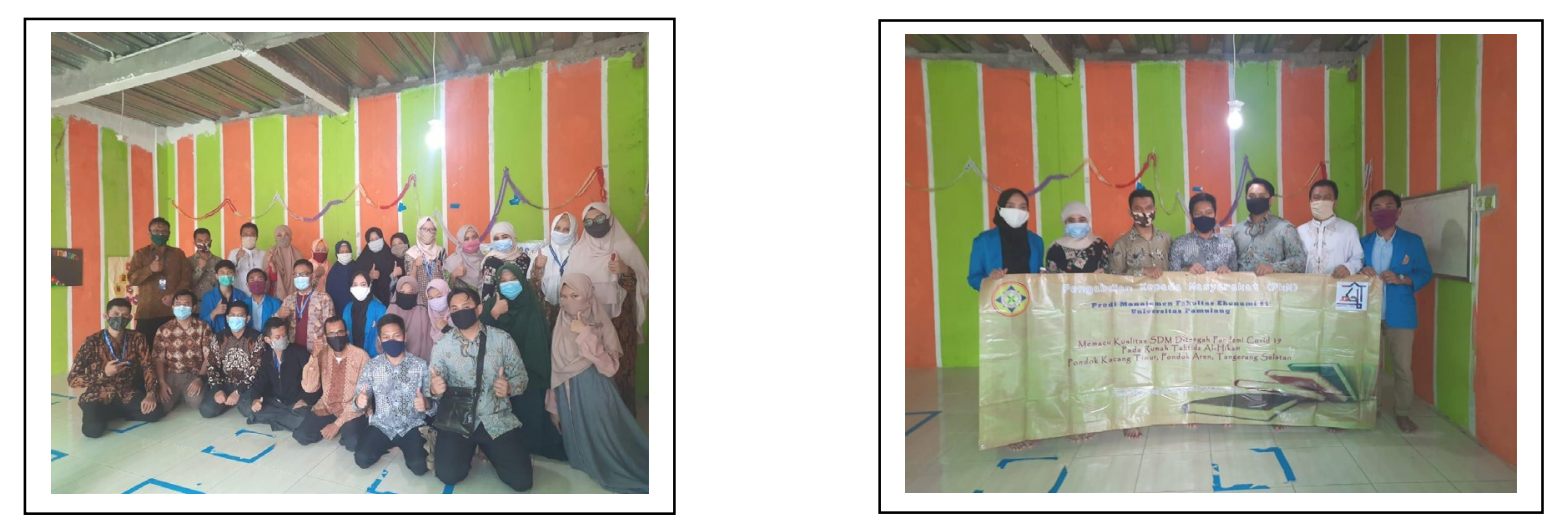

\section{Gambar 1.1 Photo Tim PKM}

Hasil kegiatan pengabdian kepada masyarakat di rumah tahfidz Al Hikam berjalan dengan lancar meski pada masa pandemi namun dengan tetap melaksankan protokol kesehatan sesuai anjuran pemerintah setempat. Untuk memacu kualitas SDM di Rumah Tahfidz Al Hikam, peningkatan kualitas SDM lebih ditekankan pada penguasaan pengetahuan, keterampilan, dan teknologi yang dibutuhkan oleh dunia kerja dalam upaya peningkatan efisiensi dan efektivitas proses produksi dalam mempertahankan keseimbangan ekonomi. Hal ini jelas terlihat dengan terealisasinya keinginan SDM Rumah tahfidz Al Hikam untuk dapat meningkatkan diri dengan mengikuti jenjang pendidikan ke tingkat yang lebih tinggi yaitu S1/S2/S3. Keinginan untuk menembus era globalisasi terlihat dengan jelas dalam wujud keinginan untuk belajar sepanjang hayat. Tidak sedikit SDM yang ingin meningkatkan kualitas dirinya. Orientasi pendidikan adalah menyiapkan tenaga kerja (SDM) terdidik, terampil, dan terlatih (berkualitas) sesuai dengan kebutuhan pasar kerja dalam masyarakat. Dalam pendidikan hal itu diimplikasikan lewat kurikulum yang bernuansa Islami di setiap jenjang dan jenis pendidikan, sehingga diharapkan akan dilahirkan SDM yang lebih berkualitas untuk mengisi lowongan kerja yang tersedia di setiap institusi. 


\section{KESIMPULAN DAN SARAN}

\section{Kesimpulan}

Pendidikan berkelanjutan merupakan salah satu alternatif dalam peningkatan kualitas SDM. Berbagai pendekatan perlu dilakukan agar peningkatan kualitas SDM ini terlaksana dengan baik dan cepat. Walaupun krisis ekonomi belum berlalu di negara kita, ditambah dengan gejolak politik yang seakan-akan tak kunjung reda, kehidupan ini berjalan terus tanpa henti. Kebutuhan demi kebutuhan terus diperlukan, tidak terkecuali kebutuhan akan pendidikan. Oleh karena itu dalam menghadapi persaingan global, utamanya SDM Rumah tahfidz Al Hikam dapat lebih mengembangkan kompetensi dengan pengembangan SDM.

\section{Saran}

Kami mengemukakan beberapa saran yang barangkali ada manfaatnya bagi peningkatan kualitas SDM di Rumah Tahfidz Al Hikam. Adapun saran-saran tersebut adalah sebagai berikut:

1. Peningkatan kualitas SDM merupakan keharusan yang mutlak diperlukan. Oleh sebab itu, peningkatan kualitas SDM harus segera direalisasikan.

2. Era globalisasi menghadirkan persaingan yang ketat merupakan tantangan yang makin berat. Untuk itu peningkatan kualitas SDM melalui pendidikan berkelanjutan perlu diberi bantuan kepada SDM yang ingin meningkatkan kualitas dirinya, baik bantuan material, moral mapun spiritual.

\section{DAFTAR PUSTAKA}

Andi. D. Maulida. H. Rizka. I. Abid. M. Wiguna. M. (2020). Memotivasi Siswa-Siswi SMK Muhammadiyah Parung-Bogor Menjadi Siswa-Siswi Unggulan Sebagai Persiapan Memasuki Jenjang Perguruan Tinggi Dan Dunia Kerja. Jurnal Pengabdian Dharma Laksana 2(2), 127-131

Atmani, Hastini Dwi, (2015). “Investasi Sumber Daya Manusia Melalui Pendidikan”. Jurnal DinamikaPembangunan.Vol.2No1/Juli 2005.

Bahreisy, Hussein. (2010). Himpunan Hadist Pilihan: Hadist Shahih Bukhari. Surabaya: A1 Ikhlas.

Djojonegoro, Wardiman. (2015). Peningkatan Kualitas Sumber Daya Manusia untuk Pembangunan. Jakarta: Depdikbud.

Qurbani. D. Utomo. SB. Maulida. H. Supardi. S. Oktrima. B. (2020). Motivasi Untuk Meningkatkan Kinerja Sumber Daya Manusia Pada Kelurahan Pisangan. Jurnal Abdimas Tri Dharma Manajemen, 1(2), 56-66.

Dumilah, R., Sunarto, A., Solihin, D., \& Maulida, H. (2020). PELATIHAN PEMANFAATAN MEDIA SOSIAL UNTUK PROMOSI. DEDIKASI PKM, 1(1), 2633.

Engkoswara. (2011). Paradigma Manajemen Pendidikan Menyongsong Otonomi Daerah. Bandung:Yayasan Amal Keluarga.

Freshka Hasiani. S, (2015). “Analisis Kualitas Sumber Daya Manusia Dan Pengaruhnya Terhadap Pertumbuhan Ekonomi Di Kabupaten Pelalawan” Jurnal Jom FEKON Vol. 2 No. 2 Oktober 2015. 
Freddie Yeremia Christanto dan Thomas Santoso , "Analisis Pelatihan Dan Pengembangan Sumber Daya Manusia Di Pt Wahana Kosmetika Indonesia" Jurnal AGORA Vol. 2, No. 2, (2014)

Hasibuan, Malayu, S.P. 2017. Manajemen Sumber Daya Manusia. Jakarat: BumiAksara. Hasibuan, M. (2008).Manajemen Sumber Daya Manusia. Jakarta: Bumi Aksara.

Hassan, A. (2017). Human Resource Development and Organizational Values. Journal of European Industial Training , 445

Kartadinata, Sunaryo. 2017. Pendidikan dan Pengembangan SDM Bermutu Memasuki Abad XXI. Purwokerto: Makalah Konvensi.

Kasmawati.(2012). Prinsip-prinsip Dasar Pengembangan Sumber Daya Manusia. Jurnal UIN Alauddin Makassar, 94.

Mangkunegara, A. P (2013).Manajemen Sumber Daya Manusia Perusahaan. Bandung: PT Remaja Rosdakarya

Poespowardojo, Soerjanto, 2017, Peran Pancasila dalam Pembangunan Nasional,Jakarta: Lemhanas. Tilaar, H.A.R. (1998). Beberapa Agenda Reformasi Pendidikan Nasional dalamPerspektif Abad 21. Magelang: Tera Indonesia.

Sanusi, Achmad. 2018. Pendidikan Alternatif. Bandung:Program Pascasarjana dan PT Grafindo Media Pratama.

Siagian, Sondang P. 2018. Manajemen Sumber Daya Manusia. Jakarta:Bumi Aksar 